\section{The War That Never Was}

\author{
Kenneth W. Kemp iD
}

https://doi.org/10.54739/76y7

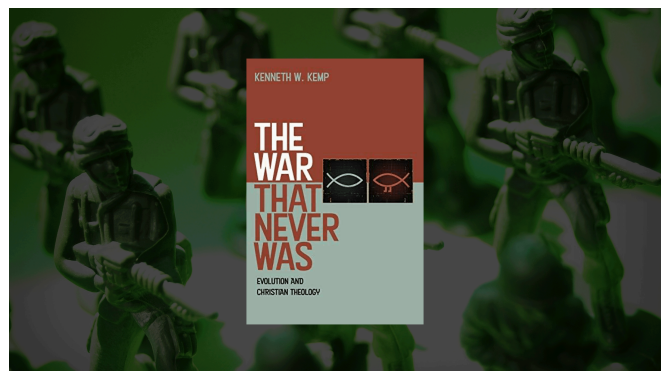

ne of the enduring myths of our age is that Western intellectual history includes a long-running war between science and theology (or sometimes religion generally)-a war in which the fight was once over the sphericity of the earth and its place in relation to the sun, planets, and stars; a war in which the fight is at present not over the structure of the universe but over its origin and history. The purpose of my book is to tell the history of the relationship between the paleoetiological sciences [the science of "ancient causes"] and Christian theology in a way that demonstrates [that the Warfare Thesis is profoundly mistaken].

The Warfare Thesis fails for three reasons.

First, the thesis presupposes that the line between scientific matters and theological matters is fairly clear. In fact, the lines were not clear; they needed to be drawn, and sometimes redrawn in light of new concepts and new knowledge.

Second, the Warfare Thesis suggests that the controversies (whether over substantive matters or over the exact location of lines of demarcation) saw scientists arrayed on one side of the issue and theologians arrayed on the other. The warfare, when that is the correct term at all, was often driven as much by the clash between new ideas and old ideas as it was by any clash between the defenders of scientific ideas and the defenders of theological ones.

Finally, the thesis suggests that what conflict there was was always due to the unreasoning resistance of theologians to new ideas. In

Kenneth W. Kemp (PhD, Notre Dame) is an emeritus professor of philosophy at the University of St. Thomas in St. Paul Minnesota. His previous work has included " Science, Theology, \& Monogenesis," " Scientific Method and Appeal to Supernatural Agency," "The Virtue of Faith in Theology, Natural Science, and Philosophy," and " Religion \& the Science Classroom." The passages below have been excerpted from his new book, The War That Never Was: Evolution \& Christian Theology (Cascade, 2020). He also recently reviewed The Genealogical Adam and Eve from a Catholic perspective. fact, irenicists and polemicists, moderates and over-reachers, can be found among evolutionists and among anti-evolutionists, among scientists and among theologians. Aggressors, when the term is appropriate at all, can never be identified with science or theology generally. At most, the aggressors are particular segments of the scientific or theological community.

The Warfare Thesis both oversimplifies and distorts the relations between science and theology on questions of the origins of the world, of biological species, and of man. Nevertheless, it would be folly to deny that there have been, and continue to be, tensions over these issues. If one is not to understand these tensions as the product of "the conflict of two contending powers," how is one to explain them?

Tension between science and religion generally arises as a result of the necessity of rethinking and adjusting the frontier between science and theology. The attempt to make some kind of synthesis of what we learn from the scientific method and what we learn from revelation (and from philosophical theology) is natural and proper. Sometimes, however, new scientific ideas require a rethinking of a wellestablished synthesis.

Rethinking is never easy and meets naturally with resistance on the part of those confident in the value of the old synthesis, suspicious of the new, and, often, not much worried about the scientific results that seem to make revision advisable. This is all made particularly difficult by the fact that each of the primary participants in the discussion of whether a new synthesis is necessary and, if so, what it should look like-the scientists and the theologians-will generally have real expertise only in their own field and thus will fail to appreciate the complexities on the other side of the frontier. In addition, there are often differences in (and differences in the assessment of) the risks of being wrong in each direction. Will greater harm be done by false scientific theories or by false religious doctrines?

Sometimes, to be sure, the source of the problem is the unreflective conservatism of theologians (or other religious believers) who, as their fellow-believers often point out to them, have mistaken theological opinions about the truths of revelation. This unreflective conservatism has sometimes included intemperate attacks, both rhetorical and political, on science. At other times, however, the source of the problem is rather the aggressive scientism, agnosticism, or atheism of scientists (or of science-enthusiasts) who fail to distinguish between the genuine fruit of scientific inquiry and the naturalistic or atheistic philosophy in which they manage to entangle it. This entanglement often leads to scientistic or otherwise uninformed attacks on religious doctrines or even on religion itself. 
The use of the Warfare Thesis as a lens through which to view the relation between science and theology or religion invites its adherents to see as confirmations of the thesis incidents that are not that at all. It does not bring the history of science (or the nature of theology or religion) into focus. Indeed it often distorts each of these subjects. One can only hope that it will soon cease to be a theme in popular intellectual culture.

\section{References}

Kenneth W. Kemp. The War That Never Was, 2020.

Used with permission from Wipf and Stock Publishers. The feature image's background is from Pixabay. 